\title{
The efficacy of Alahmady ring implantation in the management of neovascular glaucoma
}

\author{
This article was published in the following Dove Press journal: \\ Clinical Ophthalmology \\ 20 March 2017 \\ Number of times this article has been viewed
}

\author{
Alahmady H Alsmman \\ Gamal Radwan \\ Mohammed Elagouz \\ Usama Ali Mohammed \\ The Department of Ophthalmology, \\ Sohag Faculty of Medicine, Sohag \\ University, Sohag, Egypt
}

Purpose: To evaluate the efficacy and safety of Alahmady ring implantation in the management of neovascular glaucoma.

Methods: A total of 15 eyes of 15 patients with intractable neovascular glaucoma with intraocular pressure (IOP) $\geq 28 \mathrm{mmHg}$ not responding to medical treatment were retrospectively analyzed. All patients had poor visual acuity and underwent Alahmady ring implantation. The ring was designed from fenestrated silicon tube used in lacrimal surgeries and was implanted subsclerally after passing it through the anterior chamber. Patients were followed up for at least 24 months. Success in this study was defined based on IOP $\geq 8 \mathrm{mmHg}$ and $<21 \mathrm{mmHg}$, with not more than 1 glaucoma drug, and improvement of patient symptoms and signs with maximum use of beta blocker as antiglaucoma drug.

Results: A total of 15 eyes of 15 patients ( 9 males [60\%] and 6 females [40\%]) were analyzed in this study. The mean IOP before surgery was $38.6 \mathrm{mmHg}$ (standard deviation [SD]: 6.98) and it was $14.05 \mathrm{mmHg}(\mathrm{SD}=7.57)$ after surgery. The follow-up range was $24-36$ months. Success of silicon drainage device was defined as an IOP $<21 \mathrm{mmHg}$ on the last follow-up visit. Medications included only beta-blockers and topical steroids for those who were without severe complications or for those who were not in a condition to undergo a further glaucoma surgery.

Conclusion: Alahmady ring implantation proves to be a good surgical option for neovascular glaucoma; however, a longer follow-up period is recommended.

Keywords: refractory glaucoma, glaucoma device, failed trabeculectomy

\section{Introduction}

Neovascular glaucoma (NVG) remains a great challenge to ophthalmologists. It is an aggressive type of secondary glaucoma with underlying severe ocular pathology poorly responding to conventional glaucoma drugs and also with high failure rate in conventional glaucoma surgeries. ${ }^{1}$

Coats $^{2}$ in 1906 first described new vessel formation on the iris (rubeosis iridis) in patient eyes with central retinal vein occlusion. Weiss et $\mathrm{al}^{3}$ in 1963 introduced the term "neovascular glaucoma" that is now widely accepted. NVG has been reported with many ocular diseases; the most common diseases are proliferative diabetic retinopathy, ischemic central retinal vein occlusion, and ocular ischemic syndrome. ${ }^{4}$ The main pathological process in these diseases is retinal ischemia. However approximately $3 \%$ of NVG cases are due to inflammation without retinal ischemia. ${ }^{5}$ The pathology well known as ischemia triggers the release of vascular endothelial growth factor (VEGF), interleukin, and other angiogenic factors that diffuse into the anterior segment, resulting in new vessels formation at the iris (NVI), and anterior chamber angle (NVA). ${ }^{6-8}$

In the early stages of NVI and NVA, patients may have normal intraocular pressure (IOP), but later on the fibrovascular scaffolding of these vessels proliferates across
Correspondence: Alahmady H Alsmman The Department of Ophthalmology, Sohag Faculty of Medicine, Sohag University, 21 Anahda street, 82524 Sohag, Egypt

Tel +20 I I III0 2698

Email alahmady20@yahoo.com $\mathrm{BY}$
hC for commercial use of this work, please see paragraphs 4.2 and 5 of our Terms (https://www.dovepress.com/terms.php). 
the angle and IOP becomes severely elevated. Ultimately, if this condition is not properly treated, this fibrovascular proliferation contracts and produces synechial angle closure and ectropion uveae with severe elevation of IOP, thereby damaging the optic nerves with subsequent blindness. ${ }^{9}$

Two main criteria are to be focused on in the management of NVG. The first is to decrease the IOP either by prescribing medicines or surgery or by both. The second is to decrease retinal ischemia and consequently decrease VEGF, which is essential for long-term treatment. However, panretinal photocoagulation remains the mainstay treatment. It decreases VEGF release from ischemic retina. Recently, use of anti-VEGF agents has been found to be helpful in the rapid regression of neovascularization with widespread clinical use nowadays. ${ }^{10,11}$

Medical treatment of NVG includes topical beta-blockers, carbonic anhydrase inhibitors, prostaglandin agonists, alphaadrenergic agonists, oral carbonic anhydrase inhibitors, topical steroid therapy, and cycloplegic drugs. Surgical management is indicated only when medical therapy fails to control IOP. However, the long-term success rate of trabeculectomy is only moderate due to severe inflammation encountered with NVG eyes. Adjunctive therapy with trabeculectomy such as the use of 5-fluorouracil and mitomycin $\mathrm{C}$ showed better success rates in the early postoperative period, which decreased with longer-term follow-up. ${ }^{12,13}$

In recent years, glaucoma drainage implants (GDI) markedly improved long-term prognosis in NVG, the main cause of success is the mechanical mechanism of decreasing the IOP which is independent from ocular inflammation which is the main cause of failure in filtering bleb. ${ }^{14}$ The use of GDI is limited due to the difficulty faced during implantation; also GDI needs healthy ocular tissues like conjunctiva and tenon capsule as it has a relatively large exposure area. As the implant is highly expensive, use of glaucoma implant becomes a difficult choice, especially in developing countries. In this study, we attempted to design a new implant (Alahmady ring) from silicon tube widely used in lacrimal passages, which is cost-effective and a simple, effective, and safe technique. Small exposure area enables us to perform surgery, even with repeated previous surgeries and/or excessive fibrosis. In this work, we attempted to study the safety and efficacy of this implant in cases of NVG.

\section{Materials and methods}

This retrospective study was performed in Sohag Faculty of Medicine between March 2013 and April 2014 with a follow-up for at least 24 months. In this study, 15 eyes of
15 patients with $\mathrm{NVG}$ with IOP $\geq 28 \mathrm{mmHg}$ not responding to medicines, such as topical beta-blockers, alpha-agonists, topical steroids, atropines, and systemic carbonic anhydrase inhibitors, were analyzed. Preoperative evaluation of all patients included meticulous history taking, history of previous ocular diseases, and history of laser treatment and the number of times the treatment was given. Previous surgical intervention and previous diagnosis of any ocular diseases were done by any ophthalmologist. Visual acuity assessment by Snellen's chart and converted to Log Mar. In patients with poor visual acuity perception of light and projection of rays from all 4 directions were tested in all cases with color evaluation by discrimination of red and green colors by use of colored filters in glasses trial set. IOP was measured by tonopen (Reichert Tono-Pen Tonometer). A meticulous anterior segment examination and posterior segment examination were done by slit lamp bio-microscopy including anterior chamber (AC) examination by Gonio lens. Indirect ophthalmoscopy and fluorescein angiography were performed in all patients with clear media to determine the severity of ischemia and the presence of other ocular comorbidities.

All patients underwent implantation of Alahmady ring that was designed from Eagle silicon tube used in lacrimal surgeries. Figures 1 and 2 show how a ring is formed from a silicon tube, which is implanted subsclerally after passing it through an AC. Figure 3 shows how a metal probe is passed and Figure 4 shows how the silicon tube is passed through the AC. Figure 5 shows how a metal probe is passed through the silicon tube. Figure 6 shows Alahmady ring after formation. Figure 7 shows the Alahmady ring after cut near penetration. Figure 8 shows the closure of the scleral flap

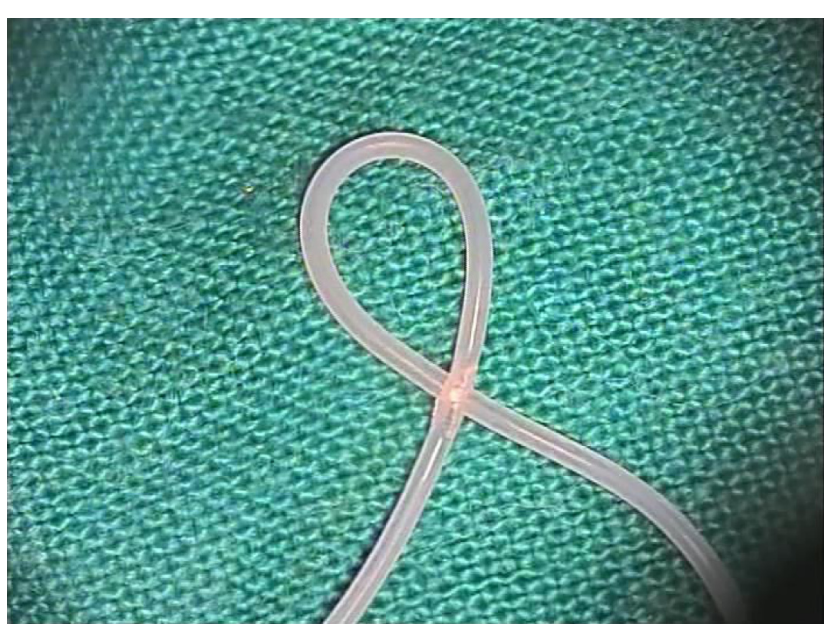

Figure I Alahmady silicon ring. 


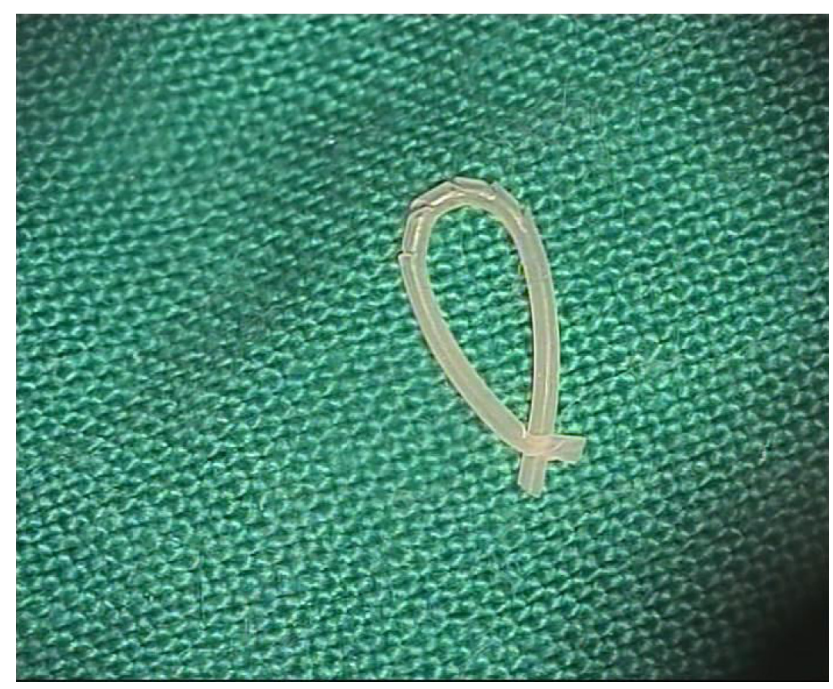

Figure 2 Alahmady silicon ring after fenestration.

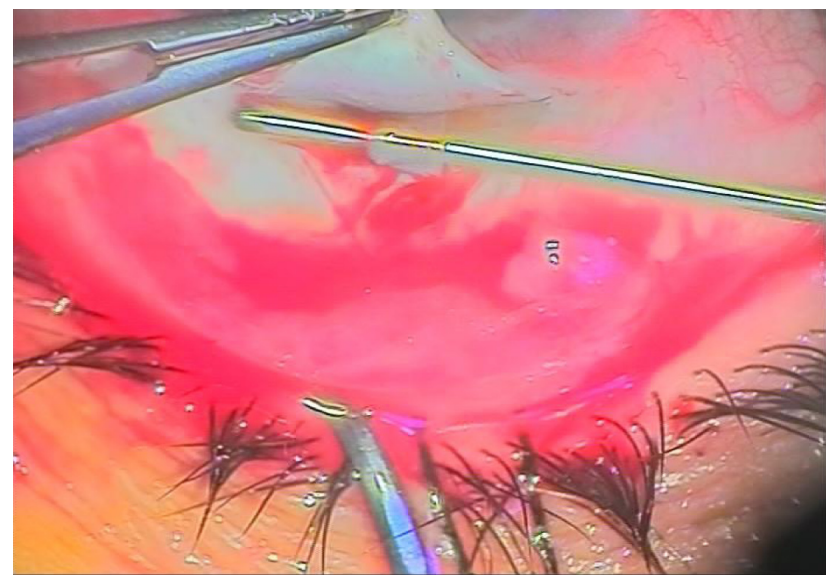

Figure 3 Passage of a metal probe through the anterior chamber.

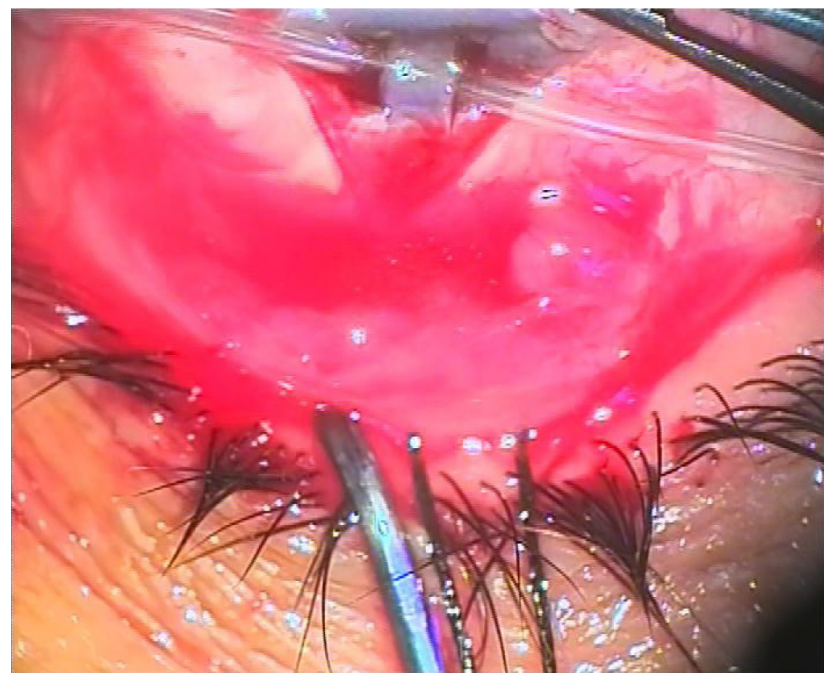

Figure 4 Passage of a silicon tube through the anterior chamber.

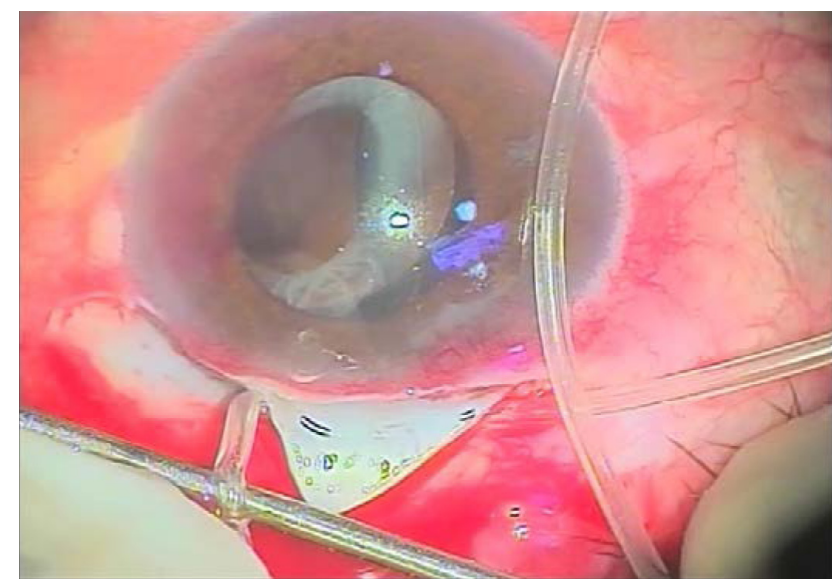

Figure 5 Passage of the metal probe through the silicon tube.

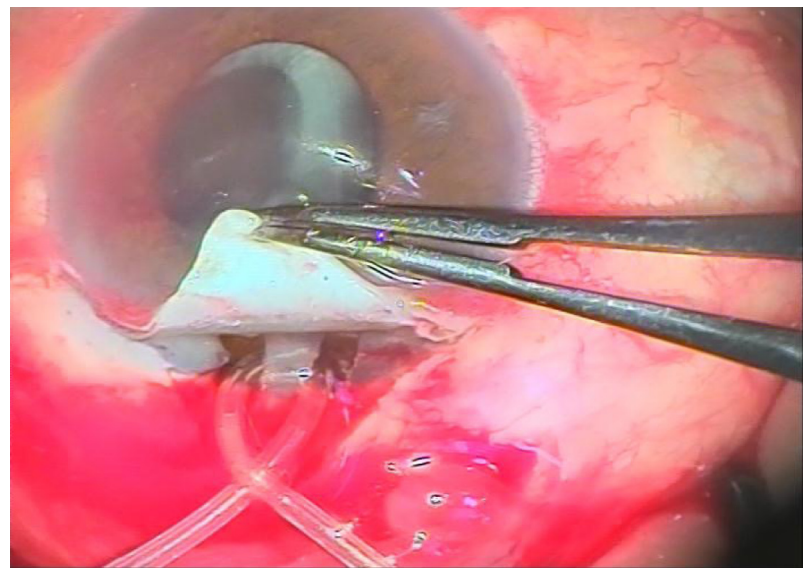

Figure 6 Alahmady ring after formation.

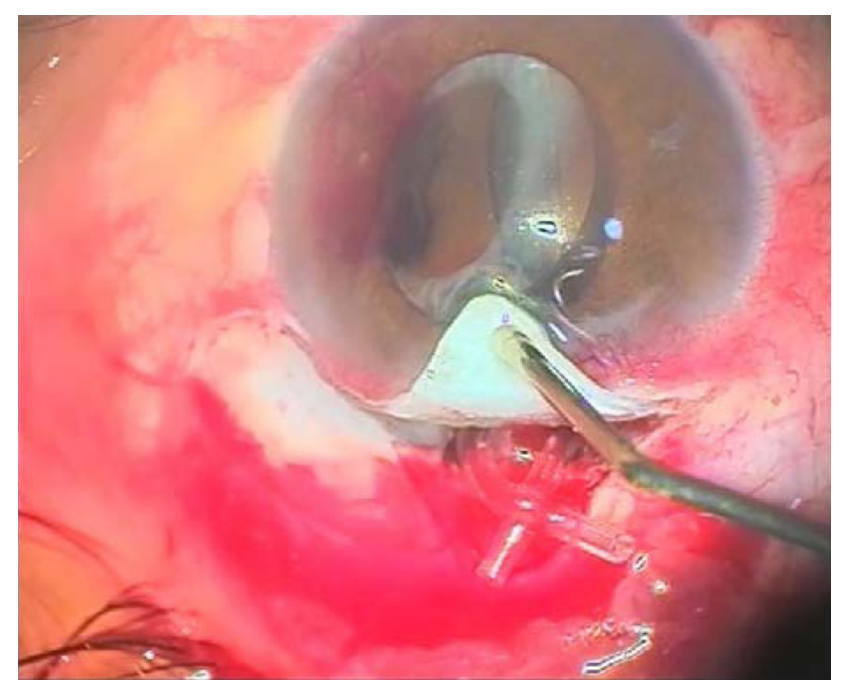

Figure 7 Alahmady ring after cutting the silicon tube near penetration. 


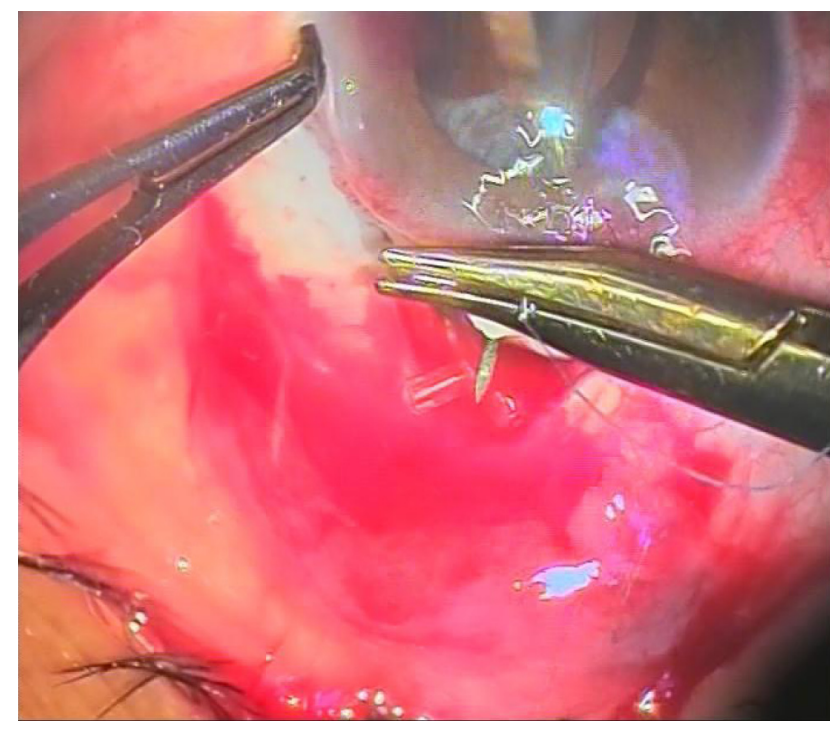

Figure 8 Closure of the scleral flap over the ring.

over the ring. Figure 9 shows the gonioscopy procedure with the tube in the AC.

Both general and local anesthesia were used: 9 patients $(60 \%)$ were given general anesthesia and 6 patients $(40 \%)$ local anesthesia ( $3 \mathrm{~mL}$ lidocaine retrobulbar anesthesia with $0.5 \mathrm{~mL}$ lidocaine injected in the subconjunctival region of upper fornix). All surgeries were performed by the same surgeon and the same surgical technique was followed for all patients. Conjunctival dissection was performed with fornix-based conjunctival flap. A limbus-based triangular scleral flap was raised into the clear cornea with blade no 15. Then 2 microtrabeculectomies, each one is $(1 \mathrm{~mm}$ thickness) with $2.5 \mathrm{~mL}$ in between both sides of the flap. After that the silicon tube, which was fenestrated manually

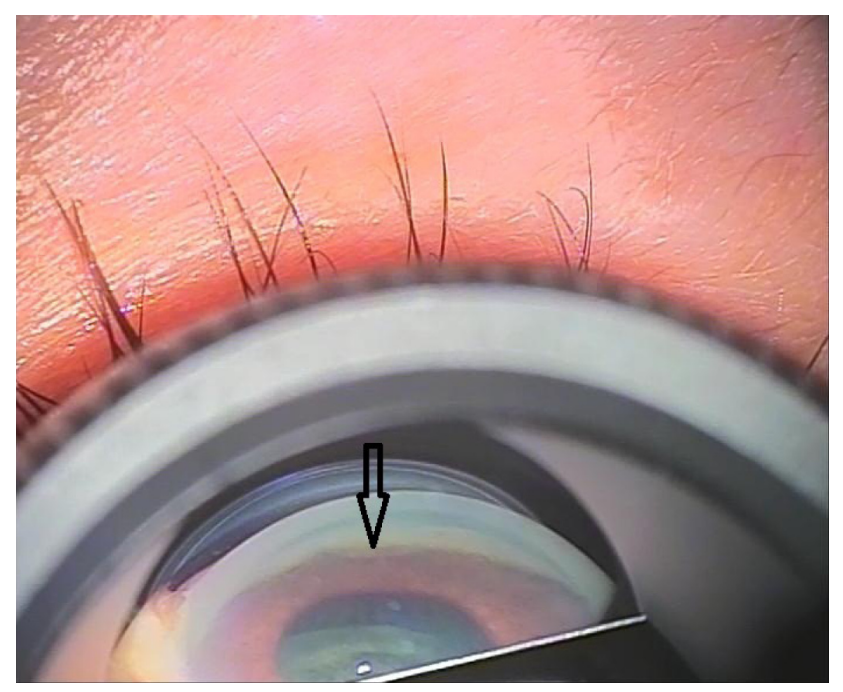

Figure 9 Gonioscopy showing the tube in the anterior chamber. by $2.2 \mathrm{~mL}$ of keratome, was inserted using a metal probe by microtrabeculectomy procedure into the $\mathrm{AC}$ and then out of the AC by contralateral microtrabeculectomy. After passing the tube into the $\mathrm{AC}$, the tube was punctured by sharp knife 20. $3 \mathrm{~mL}$ from fenestration was done before then passing the metal probe through the silicon tube to form Alahmady ring by the tube. The tube was cut adjacent to the penetration site and covered by a scleral flap. The scleral flap and conjunctiva were closed by virgin silk $8 / 0$. Postoperative treatment included topical antibiotic for 1 week, frequent topical corticosteroid for 1 month, atropine for 2 weeks once daily, and systemic anti-inflammatory drugs.

Patients were followed up for at least 24 months. Success in this study was defined as IOP less than $21 \mathrm{mmHg}$, with or without the use of a beta blocker as a single anti glaucoma drug, local steroid, and atropine. Postoperative examination was done after 6 hours, 24 hours, 3 days, 1 week, and then every week for 3 months and then every month for 2 years.

During each visit, measurement of IOP, slit lamp examination, vision evaluation, and gonioscopy were performed.

A written consent was obtained from all the patients for the surgery and this study after fully describing the surgery and its possible complications. All patients agreed to undergo this surgery due to its novelty and also because all had poor vision. They were ready to undergo destructive surgeries and even enucleation due to their long-term suffering.

The ethics committee of the Sohag Faculty of Medicine approved this study.

\section{Statistical analysis}

Data were collected and analyzed by SPSS for Windows (version 16.0, Chicago, Illinois, USA).

Preoperative and postoperative variables were compared by paired $t$-test. $P<0.05$ was considered to be statistically significant.

\section{Results}

Fifteen eyes of 15 patients ( 9 males [60\%] and 6 females [40\%]) were analyzed in this study. The age of patients ranged from 46-68 years (mean age: 57.73 ). The IOP before surgery ranged from 32 to $46 \mathrm{mmHg}$ (mean IOP: $38.60 \mathrm{mmHg}$; $\mathrm{SD}=3.83)$. Postoperatively it was $15.60 \mathrm{mmHg}(\mathrm{SD}=5.34)$; 1 month after surgery; it was $18.06 \mathrm{mmHg}(\mathrm{SD}=2.86) 1$ year after surgery; and 2 years after surgery, it was $18.46 \mathrm{mmHg}$ ( $\mathrm{SD}=2.41$ ). The follow-up range was $24-36$ months (mean follow-up: 15.0-18.46). A total of 4 patients (26.67\%) already underwent glaucoma surgery (all trabeculectomy) and 4 patients $(26.67 \%)$ cataract surgery. 
Table I Demographic data of patients obtained before surgery

\begin{tabular}{ll}
\hline Patient data & Description \\
\hline Age, years & \\
Mean \pm SD & $57.73 \pm 6.52$ \\
Min-max & $(46.0-68.0)$ \\
Sex & \\
Male & $9(60.0 \%)$ \\
Female & $6(40.0 \%)$ \\
\hline
\end{tabular}

Abbreviations: max, maximum; min, minimum; SD, standard deviation.

Table 2 Clinical data of patients obtained before and after surgery

\begin{tabular}{ll}
\hline Item & Description \\
\hline Previous surgery & \\
Glaucoma & $4(26.67 \%)$ \\
Cataract & $4(26.67 \%)$ \\
No surgery & $7(46.67 \%)$ \\
Underlying cause & \\
PDR & $10(66.67 \%)$ \\
CRVO & $5(33.33 \%)$ \\
\hline
\end{tabular}

Abbreviations: CRVO, central retinal vein occlusion; PDR, proliferative diabetic retinopathy.

Table 3 IOP data of patients obtained before and after surgery

\begin{tabular}{ll}
\hline & Description $(\mathbf{m m H g})$ \\
\hline IOP before surgery & $38.60 \pm 3.83(32.0-46.0)$ \\
IOP at I month & $15.60 \pm 5.34(5.0-23.0)$ \\
IOP at I2 months & $18.06 \pm 2.86(14.0-25.0)$ \\
IOP at 24 months & $18.46 \pm 8.46(15.0-18.46)$ \\
\hline
\end{tabular}

Note: Data presented as mean \pm standard deviation (range).

Abbreviation: IOP, intraocular pressure.
All patients were under treatment for NVG; they were prescribed topical beta-blockers, alpha agonists, topical steroids, atropines, and systemic carbonic anhydrase inhibitors.

All patients suffered from redness of eye and pain that ranged from discomfort to severe agonizing pain. After surgery, all patients reported improvements with no agonizing pain. Only 5 patients $(33.33 \%)$ reported a slight discomfort. Persistent redness was observed in 10 eyes (66.67\%).

Table 1 shows patients' demographic data, and the mean age was 57.73 years. Of the total patients involved, $60.0 \%$ were male and $40.0 \%$ female.

Table 2 shows the data of patients who previously underwent surgery for glaucoma $(26.67 \%)$ and cataract (26.67\%), and of those who did not undergo any previous surgery (46.67\%). Regarding the underlying causes of NVG in patients, there were $(66.67 \%)$ of cases had proliferative diabetic retinopathy (PDR) and $(33.33 \%)$ had central retinal vein occlusion.

Table 3 shows the IOP data of patients obtained before and after surgery with follow-up. The preoperative IOP was 38.6 and decreased to 15.60 , after 1 month of surgery with a highly statistically significant difference $(P<0.000)$. The preoperative IOP decreased to 18.06 after 12 months of surgery $(P<0.000)$ and to 18.46 after 24 months of surgery $(P<0.000)$. According to the success criteria of our study, 3 patients (20\%) failed to obtain IOP $<21 \mathrm{mmHg}$, who were prescribed only one anti-glaucoma medication.

Table 4 shows the preoperative data of the 15 patients included in our study, whereas Table 5 shows the postoperative data of these patients.

Table 4 Preoperative data

\begin{tabular}{|c|c|c|c|c|c|c|c|}
\hline $\begin{array}{l}\text { Patient } \\
\text { number }\end{array}$ & Age (years) & Sex & IOP (mmHg) & Vision & Colour vision & Previous surgery & Underlying cause \\
\hline I & 65 & Male & 34 & Log Mar 3 & Good & Glaucoma & PDR \\
\hline 2 & 55 & Female & 37 & Log Mar I.7 & Good & No & PDR \\
\hline 3 & 57 & Female & 42 & Log Mar 2.2 & Bad & Cataract & PDR \\
\hline 4 & 46 & Female & 40 & Log Mar I.2 & Bad & No & CRVO \\
\hline 5 & 58 & Male & 37 & Log Mar I.7 & Good & Glaucoma & PDR \\
\hline 6 & 64 & Male & 33 & Log Mar 2 & Good & No & PDR \\
\hline 7 & 61 & Female & 38 & Log Mar 3 & Good & Cataract & PDR \\
\hline 8 & 60 & Male & 32 & No PL & No & Glaucoma & RD \\
\hline 9 & 68 & Male & 39 & No PL & No & Cataract & CRVO \\
\hline 10 & 54 & Male & 44 & Log Mar I.4 & Good & No & PDR \\
\hline II & 55 & Female & $4 I$ & Log Mar 2.5 & $\mathrm{Bad}$ & No & PDR \\
\hline 12 & 56 & Male & 39 & Log Mar 3 & Bad & Glaucoma & CRVO \\
\hline 13 & 52 & Male & 38 & Log Mar I.7 & Good & No & CRVO \\
\hline 14 & 67 & Male & 46 & No PL & No & Cataract & PDR \\
\hline 15 & 48 & Female & 39 & Log Mar 2.2 & Good & No & CRVO \\
\hline
\end{tabular}

Abbreviations: PL, perception of light; CRVO, central retinal vein occlusion; IOP, intraocular pressure; PDR, proliferative diabetic retinopathy. 
Table 5 Postoperative data

\begin{tabular}{|c|c|c|c|c|c|}
\hline $\begin{array}{l}\text { Patient } \\
\text { number }\end{array}$ & $\begin{array}{l}\text { IOP at } \\
\text { I month } \\
(\mathrm{mmHg})\end{array}$ & $\begin{array}{l}\text { IOP at } \\
12 \text { months } \\
(\mathrm{mmHg})\end{array}$ & $\begin{array}{l}\text { IOP at } \\
24 \text { months } \\
(\mathrm{mmHg})\end{array}$ & $\begin{array}{l}\text { Vision at } \\
24 \text { months }\end{array}$ & $\begin{array}{l}\text { Color vision at } \\
24 \text { months }\end{array}$ \\
\hline $\mathrm{I}$ & 18 & 18 & 19 & $\log \operatorname{Mar} 3$ & Good \\
\hline 2 & 19 & 19 & 19 & Log Mar I.7 & Good \\
\hline 3 & 16 & 17 & 18 & Log Mar 2 & Good \\
\hline 4 & 6 & 16 & 17 & Log Mar I & Bad \\
\hline 5 & 14 & 15 & 16 & Log Mar 1.7 & Good \\
\hline 6 & 12 & 15 & 16 & Log Mar 2 & Good \\
\hline 7 & 10 & 16 & 15 & Log Mar 3 & Good \\
\hline 8 & 16 & 18 & 19 & No PL & No \\
\hline 9 & 19 & 21 & 20 & No PL & No \\
\hline 10 & 23 & 25 & 23 & Log Mar I.3 & Good \\
\hline 11 & 17 & 18 & 18 & Log Mar 2.5 & Bad \\
\hline 12 & 20 & 20 & 21 & Log Mar 3 & $\mathrm{Bad}$ \\
\hline 13 & 17 & 18 & 19 & Log Mar I.7 & Good \\
\hline 14 & 22 & 21 & 22 & No PL & No \\
\hline 15 & 5 & 14 & 15 & Log Mar I.3 & Good \\
\hline
\end{tabular}

Abbreviations: IOP, intraocular pressure; PL, perception of light.

\section{Complications}

One patient $(6.67 \%)$ developed transient postoperative hypotony but the IOP quickly recovered within 4 days, which did not need any other intervention. One eye $(6.67 \%)$ required subsequent interventions due to conjunctival dehiscence and tube exposure. This condition was overcome by repositioning the tube and by performing conjunctival closure. Two patients (13.34\%) developed early choroidal detachment. This condition improved in the next 2 weeks on treatment with topical atropines and topical steroids with systemic non-steroidal anti-inflammatory drugs. One patient developed hyphema intraoperatively that markedly decreased by repeated wash. Minimal hyphema persisted in the next 1 week, which spontaneously resolved within 2 weeks. No serious complications such as endophthalmitis, retinal detachment, or vitrous hemorrhage were reported during the follow-up period.

\section{Discussion}

NVG is an aggressive type of glaucoma, which often results in poor visual outcomes. Most of the patients with NVG have a severe underlying systemic and ocular pathology which causes NVG as a late presentation of their primary systemic and/or ocular disease. This makes NVG very difficult to treat.

Surgical intervention is indicated when medical therapy is inadequate to control IOP, particularly if synechial angle closure from NVA has occurred.

GDIs have widely been used for the treatment of complicated glaucomas including NVG. ${ }^{15-17}$

In this study, we found that the Alahmady silicon ring implant decreased the IOP from $38.60 \mathrm{mmHg}(\mathrm{SD}=3.83)$ to $15.60 \mathrm{mmHg}(\mathrm{SD}=5.34) 1$ month after surgery, which is a mean reduction of $59.5 \%$. The IOP further decreased to $18.06 \mathrm{mmHg}(\mathrm{SD}=2.86) 1$ year after surgery, which is a mean reduction of $53.2 \%$, and to $18.46 \mathrm{mmHg}(\mathrm{SD}=2.41) 2$ years after surgery, which is a mean reduction of $52.1 \%$.

In a tertiary hospital study in Oman, Ahmad glaucoma valve implant decreased the mean preoperative IOP from $37.0 \mathrm{mmHg}(\mathrm{SD}=12.1)$ to $18.4 \mathrm{mmHg}(\mathrm{SD}=10.7)$ at 3 months and to $18.0 \mathrm{mmHg}(\mathrm{SD}=14.1)$ at 1 year postoperatively. The reduction in IOP observed in the aforementioned study is slightly higher than that in our study. This difference might be due to various types of resistant glaucomas, and the aforementioned study concluded that worst results were observed in patients with $\mathrm{NVG} .{ }^{18}$

The Alahmady implant used in this study achieved an IOP lowering slightly less than that reported by Huang et al using their implant in 159 eyes of complicated glaucoma patients. They reported a success rate of $87 \%$ at the most recent follow-up examination. ${ }^{19}$

The reduction in IOP reported in this study is also slightly lower than that reported by Aung and Seah (85.5\%), who used non-valved glaucoma implants in Asian eyes. ${ }^{20}$ One of the possible reasons is that all our patients suffered from $\mathrm{NVG}$, which is associated with a much higher risk of failure compared to other types of glaucoma.

Several authors have advocated the use of bevacizumab as an adjunct to glaucoma surgery in order to facilitate surgery and improve long-term outcomes. Lavin et al undertook a large study of NVG patients, comparing those eyes treated with and without intravitreal bevacizumab with better results in previously injected patients. ${ }^{21}$ 
Risk factors for progressive failure of MMC-treated trabeculectomies included younger age and prior vitrectomy. ${ }^{11}$ In our study we did not use any adjunctive therapy as we tried to detect the effect of Alahmady ring implant without any factor that may affect success rate. Early postoperative hypotony in this study was $6.67 \%$, which was similar to other series of non-valved glaucoma implant $(5 \%-16.5 \%){ }^{22-24}$ In comparison with Huang's series, their rate of postoperative hypotony was lower. ${ }^{19}$ The majority of the postoperative complications were transient and resolved either spontaneously or with simple surgical procedures. Tube erosion through the conjunctiva occurred in 1 patient with no major complications with tube repositioning and conjunctival closure. In Lai et al's study on 65 patients with Ahmad valve implantation, only 2 eyes had erosion of the tube through the patch graft that finally required a regraft. This might be due to the fact that frozen corneoscleral patch graft was used to cover the exposed part of the tube in their study. ${ }^{25}$

According to the success criteria in our study, 3 patients (20\%) failed to obtain IOP $<21 \mathrm{mmHg}$ with only 1 antiglaucoma medication. The value thus obtained in this study is less compared to that obtained in Huang et al's study, in which Ahmad valve implant was used in 159 eyes of complicated glaucoma patients. ${ }^{19}$ The decrease in IOP values observed is also slightly lower than that observed in Aung and Seah's study, in which non-valved glaucoma implant was used in Asian eyes (85.5\%). ${ }^{20}$

Our result is better than Lai et al in total success rate as their success rate was $73.8 \%$ and they explain lower success rate due to large number of NVG involved in their study. ${ }^{25}$ However, a decreased success rate of our study might be due to NVG itself, as all the previous studies that focused on various types of resistant glaucomas obtained worst results in patients with NVG.

\section{Conclusion}

Alahmady ring implantation in NVG patients is a simple, effective, and safe technique. This ring is made of silicon tube widely used in lacrimal surgeries, which makes it cost-effective and to be widely used in developing countries; however, longer follow-up period with anti-VEGF is recommended.

\section{Disclosure}

The authors report no conflicts of interest in this work.

\section{References}

1. Wand M. Neovascular glaucoma, Chapter 51. In: Ritch R, Shields MB, Krupin T, editors. The Glaucomas-Clinical Science. 2nd ed. St. Louis: Mosby; 1996:1073-1129.
2. Coats G. Further cases of thrombosis of the central vein. Roy Lond Ophthal Hosp Rep. 1906;16:516.

3. Weiss DI, Shaffer RN, Nehrenberg TR. Neovascular glaucoma complicating carotid-cavernous fistula. Arch Ophthalmol. 1963;69:304-307.

4. Sivak-Callcott JA, O’Day DM, Gass JD, Tsai JC. Evidence-based recommendations for the diagnosis and treatment of neovascular glaucoma. Ophthalmology. 2001;108(10):1767-1776; quiz 1777, 1800.

5. Brown GC, Magargal LE, Schachat A, Shah H. Neovascular glaucoma. Etiologic considerations. Ophthalmology. 1984;91(4):315-320.

6. Casey R, Li WW. Factors controlling ocular angiogenesis. Am J Ophthalmol. 1997;124(4):521-529.

7. Tripathi RC, Li J, Tripathi BJ, Chalam KV, Adamis AP. Increased level of vascular endothelial growth factor in aqueous humor of patients with neovascular glaucoma. Ophthalmology. 1998;105(2):232-237.

8. Chen KH, Wu CC, Roy S, Lee SM, Liu JH. Increased interleukin-6 in aqueous humor of neovascular glaucoma. Invest Ophthalmol Vis Sci. 1999;40(11):2627-2632.

9. Olmos LC, Lee RK. Medical and surgical treatment of neovascular glaucoma. Int Ophthalmol Clin. 2011;51(3):27-36.

10. Moraczewski AL, Lee RK, Palmberg PF, Rosenfeld PJ, Feuer WJ. Outcomes of treatment of neovascular glaucoma with intravitreal bevacizumab. Br J Ophthalmol. 2009;93(5):589-593.

11. Wakabayashi T, Oshima Y, Sakaguchi H, et al. Intravitreal bevacizumab to treat iris neovascularization and neovascular glaucoma secondary to ischemic retinal disease in 41 consecutive cases. Ophthalmology. 2008;115(9):1571-1580.

12. Tsai JC, Feuer WJ, Parrish RK 2nd, Grajewski AL. 5-Fluorouracil filtering surgery and neovascular glaucoma. Long-term follow-up of the original pilot study. Ophthalmology. 1995;102(6):887-892; discussion 892-893.

13. Takihara $\mathrm{Y}$, Inatani $\mathrm{M}$, Fukushima $\mathrm{M}$, Iwao $\mathrm{K}$, Iwao $\mathrm{M}$, Tanihara $\mathrm{H}$. Trabeculectomy with mitomycin $\mathrm{C}$ for neovascular glaucoma: prognostic factors for surgical failure. Am J Ophthalmol. 2009;147(5):912-918, 918.e1.

14. Park UC, Park KH, Kim DM, Yu HG. Ahmed glaucoma valve implantation for neovascular glaucoma after vitrectomy for proliferative diabetic retinopathy. J Glaucoma. 2011;20(7):433-438.

15. Krupin T, Kaufman P, Mandell A, et al. Filtering valve implant surgery for eyes with neovascular glaucoma. Am J Ophthalmol. 1980;89(3):338-343.

16. Melamed S, Fiore PM. Molteno implant surgery in refractory glaucoma. Surv Ophthalmol. 1990;34(6):441-448.

17. McDonnell PJ, Robin JB, Schanzlin DJ, et al. Molteno implant for control of glaucoma in eyes after penetrating keratoplasty. Ophthalmology. 1988;95(3):364-369.

18. Shah MR, Khandekar RB, Zutshi R, Mahrooqi R. Short term outcome of Ahmed glaucoma valve implantation in management of refractory glaucoma in a tertiary hospital in Oman. Oman J Ophthalmol. 2013;6(1): $27-32$.

19. Huang MC, Netland PA, Coleman AL, Siegner SW, Moster MR, Hill RA. Intermediate-term clinical experience with the Ahmed Glaucoma Valve implant. Am J Ophthalmol. 1999;127(1):27-33.

20. Aung T, Seah SK. Glaucoma drainage implants in Asian eyes. Ophthalmology. 1998;105(11):2117-2122.

21. Lavin MJ, Franks WA, Wormald RP, Hitchings RA. Clinical risk factors for failure in glaucoma tube surgery. A comparison of three tube designs. Arch Ophthalmol. 1992;110(4):480-485.

22. Siegner SW, Netland PA, Urban RC Jr, et al. Clinical experience with the Baerveldt glaucoma drainage implant. Ophthalmology. 1995; 102(9):1298-1307.

23. Mills RP, Reynolds A, Emond MJ, Barlow WE, Leen MM. Long-term survival of Molteno glaucoma drainage devices. Ophthalmology. 1996; 103(2):299-305.

24. Egbert PR, Lieberman MF. Internal suture occlusion of the Molteno glaucoma implant for the prevention of postoperative hypotony. Ophthalmic Surg. 1989;20(1):53-56.

25. Lai JS, Poon AS, Chua JK, Tham CC, Leung AT, Lam DS. Efficacy and safety of the Ahmed glaucoma valve implant in Chinese eyes with complicated glaucoma. Br J Ophthalmol. 2000;84(7):718-721. 


\section{Publish your work in this journal}

Clinical Ophthalmology is an international, peer-reviewed journal covering all subspecialties within ophthalmology. Key topics include: Optometry; Visual science; Pharmacology and drug therapy in eye diseases; Basic Sciences; Primary and Secondary eye care; Patient Safety and Quality of Care Improvements. This journal is indexed on

Submit your manuscript here: http://www.dovepress.com/clinical-ophthalmology-journal
PubMed Central and CAS, and is the official journal of The Society of Clinical Ophthalmology (SCO). The manuscript management system is completely online and includes a very quick and fair peer-review system, which is all easy to use. Visit http://www.dovepress.com/ testimonials.php to read real quotes from published authors. 